\title{
Magnet Test Facilities
}

\author{
M. Tartaglia, L. Kokoska \\ Fermilab, APS-TD, Magnet Sector, Test \& Instrumentation Department
}

FERMILAB-POSTER-20-021-TD

\section{Vertical Magnet Test Facility (VMTF)}

Superconducting Magnets without a cryostat are tested at the APS-TD Magnet Test Facility in a re-usable vertical helium vessel. Capabilities include:

Large SC Magnet R\&D (<0.625-m OD, <3.7-m long)

Temperature: $1.9 \mathrm{~K}$ to $4.6 \mathrm{~K} \quad$ Current: up to $30 \mathrm{kA}$

Quench Protection \& Characterization, Splice Resistance, AC Loss Measurement, and magnetic measurements with warm bore tubes.

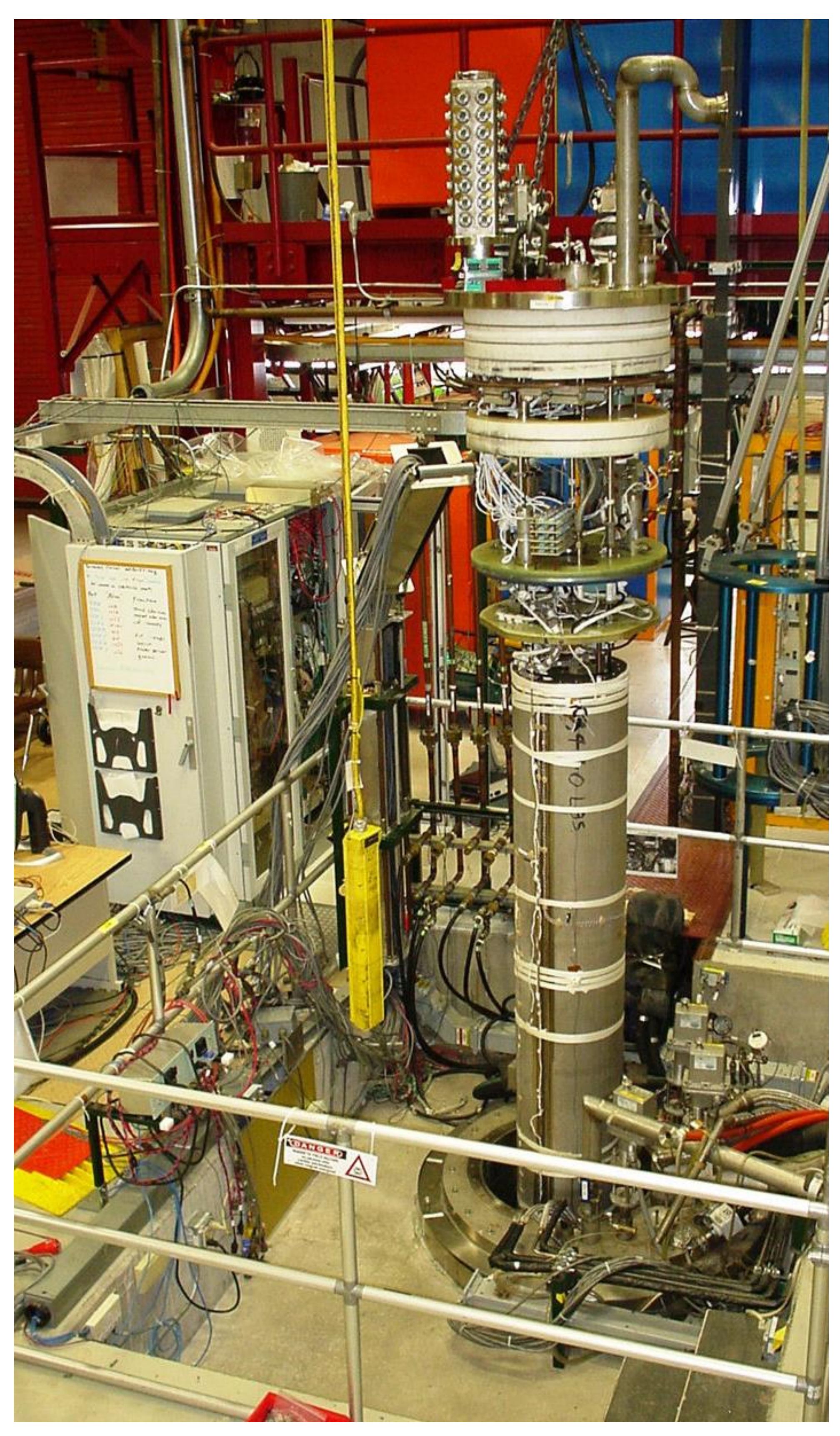

Insertion into $6 \mathrm{~m}$ deep helium cryostat

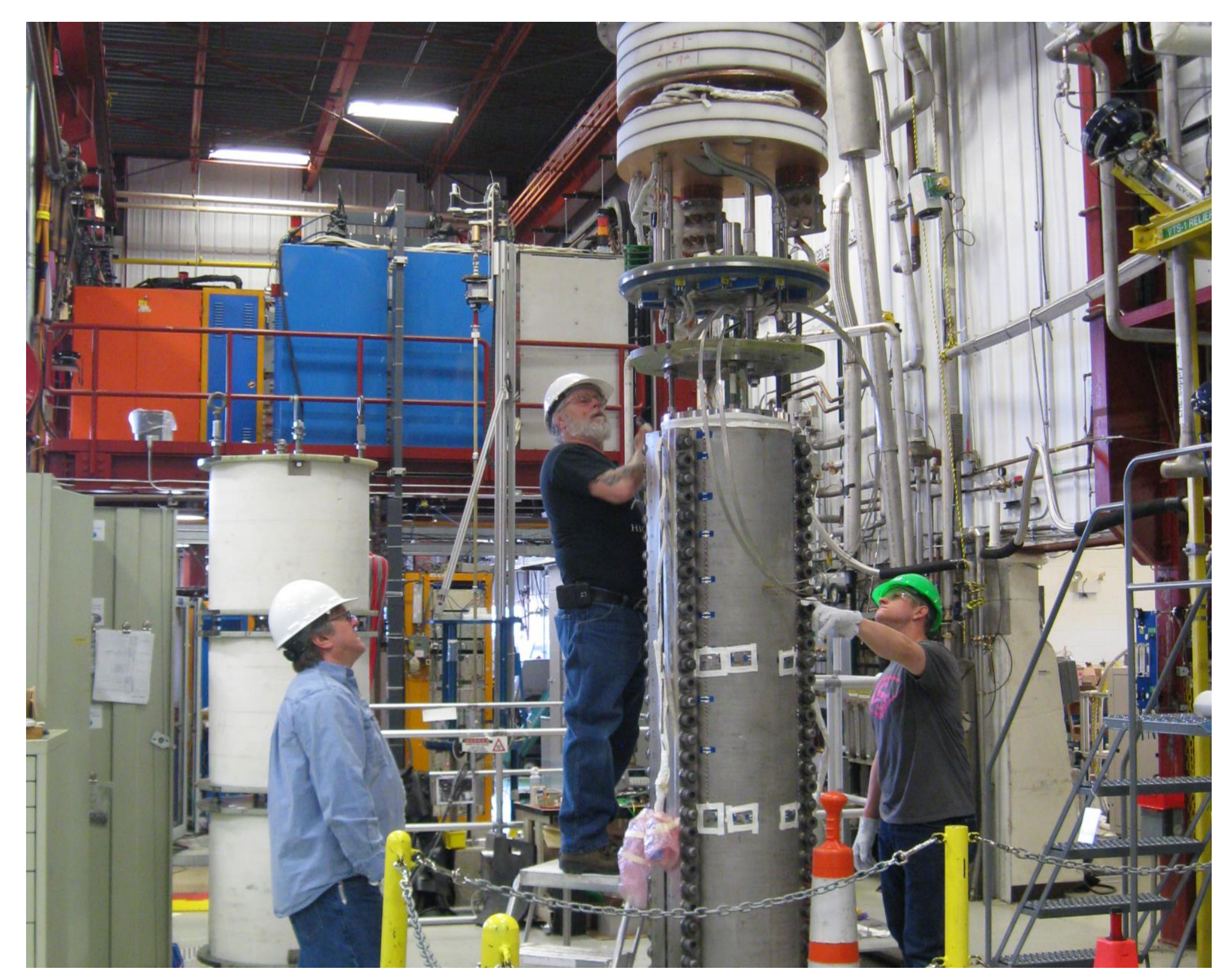

Magnet hookup to top plate assembly

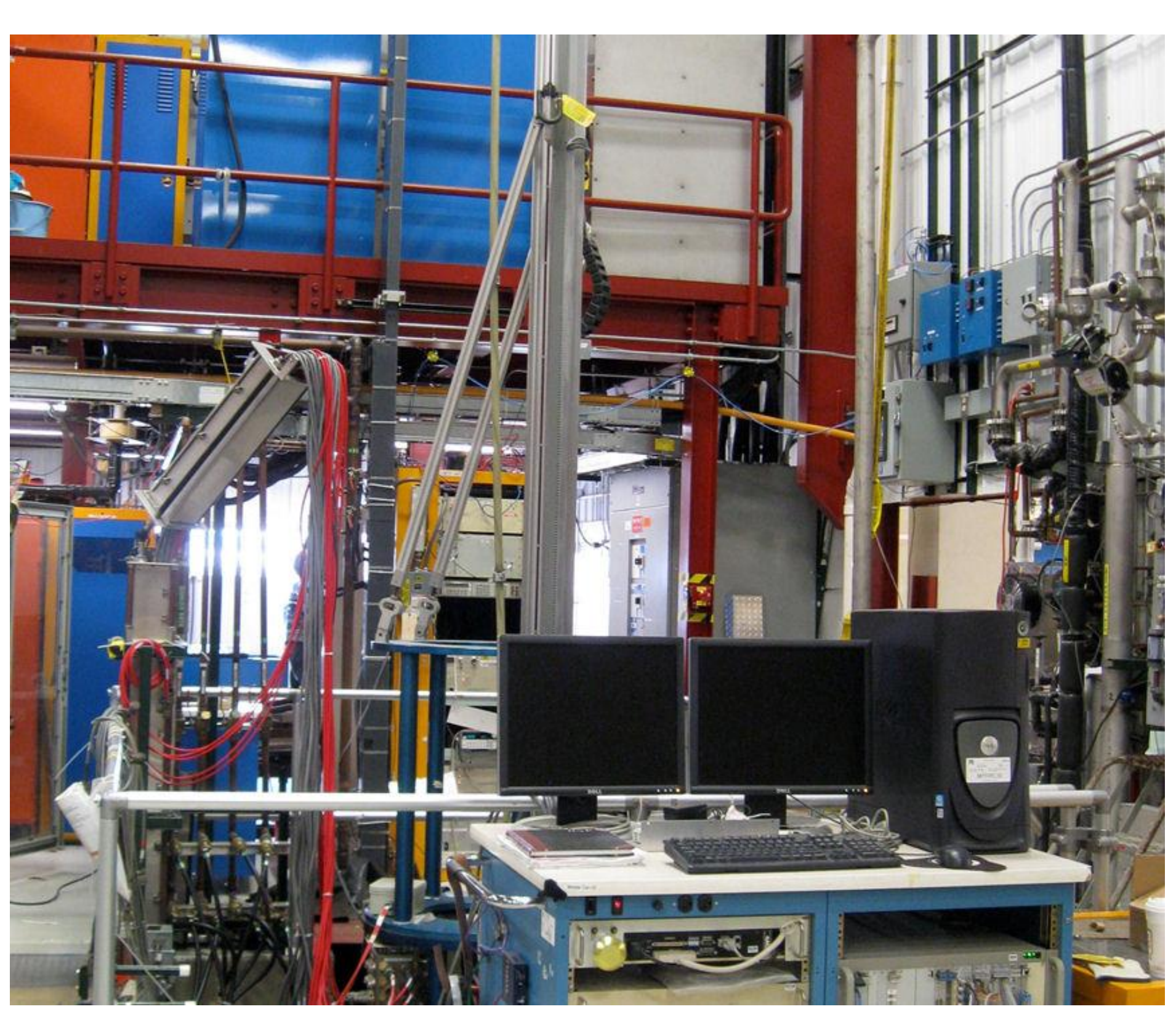

Magnetic measurement cart with rotating coil drive tower mounted over top plate

\section{Solenoid Test Facility (STF)}

Currently being used for the qualification of the Mu2e TS Production Magnets, the STF accommodates superconducting magnets that are conduction cooled to $4 \mathrm{~K}$ in an open vacuum vessel area approximately 3-m in diameter $\times 2-m$ in height.

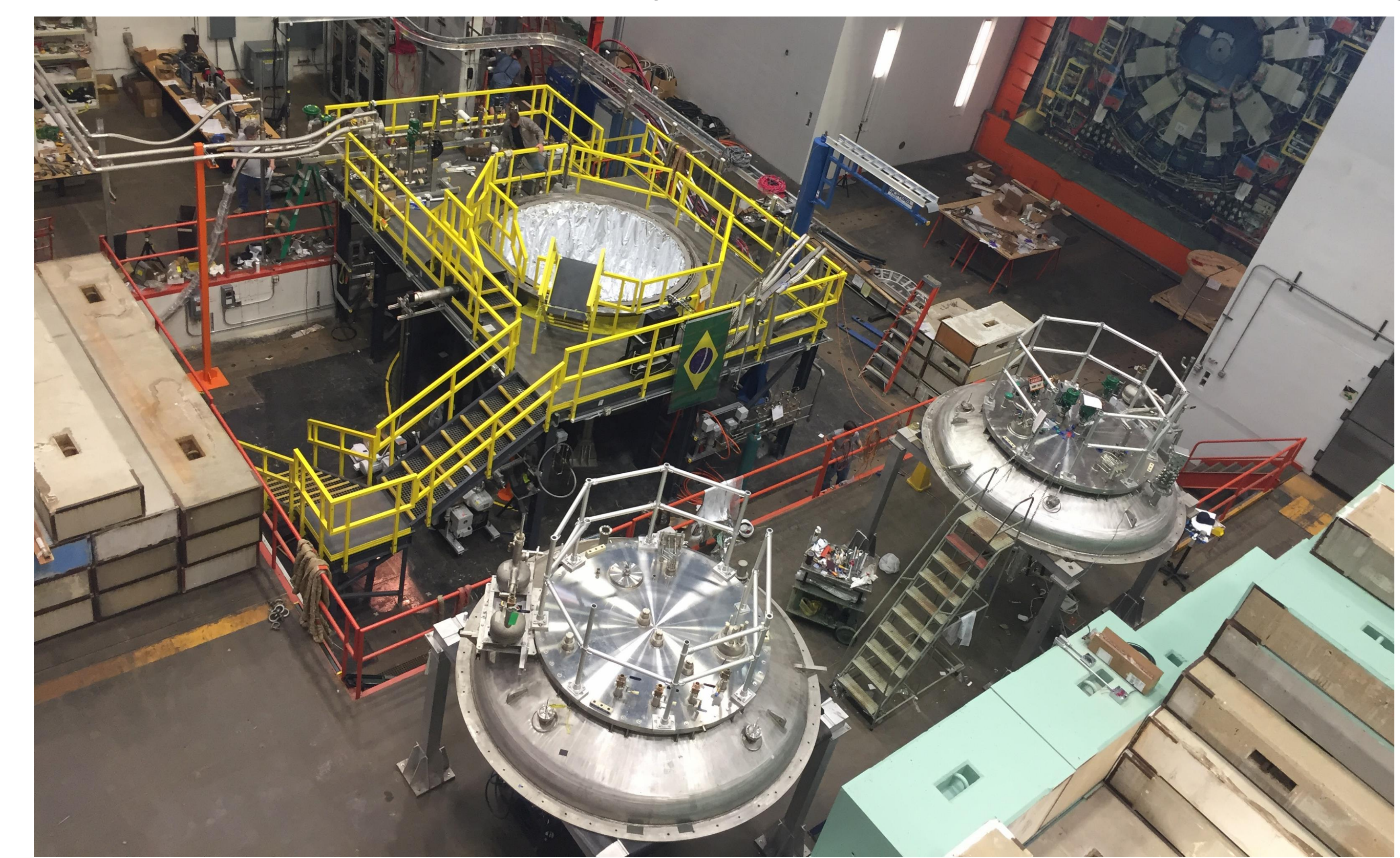

Overview of STF at HAB with staging areas, vacuum vessel, and header assemblies

\section{Test Stand 4 - US HL-LHC Cryo-Assembly Test Area}

Superconducting magnets with a cryostat are tested horizontally on Test Stand 4. The stand will be the location for the cold testing and qualification of the US HiLumi-LHC Cryo-Assemblies prior to shipment and installation at the LHC.

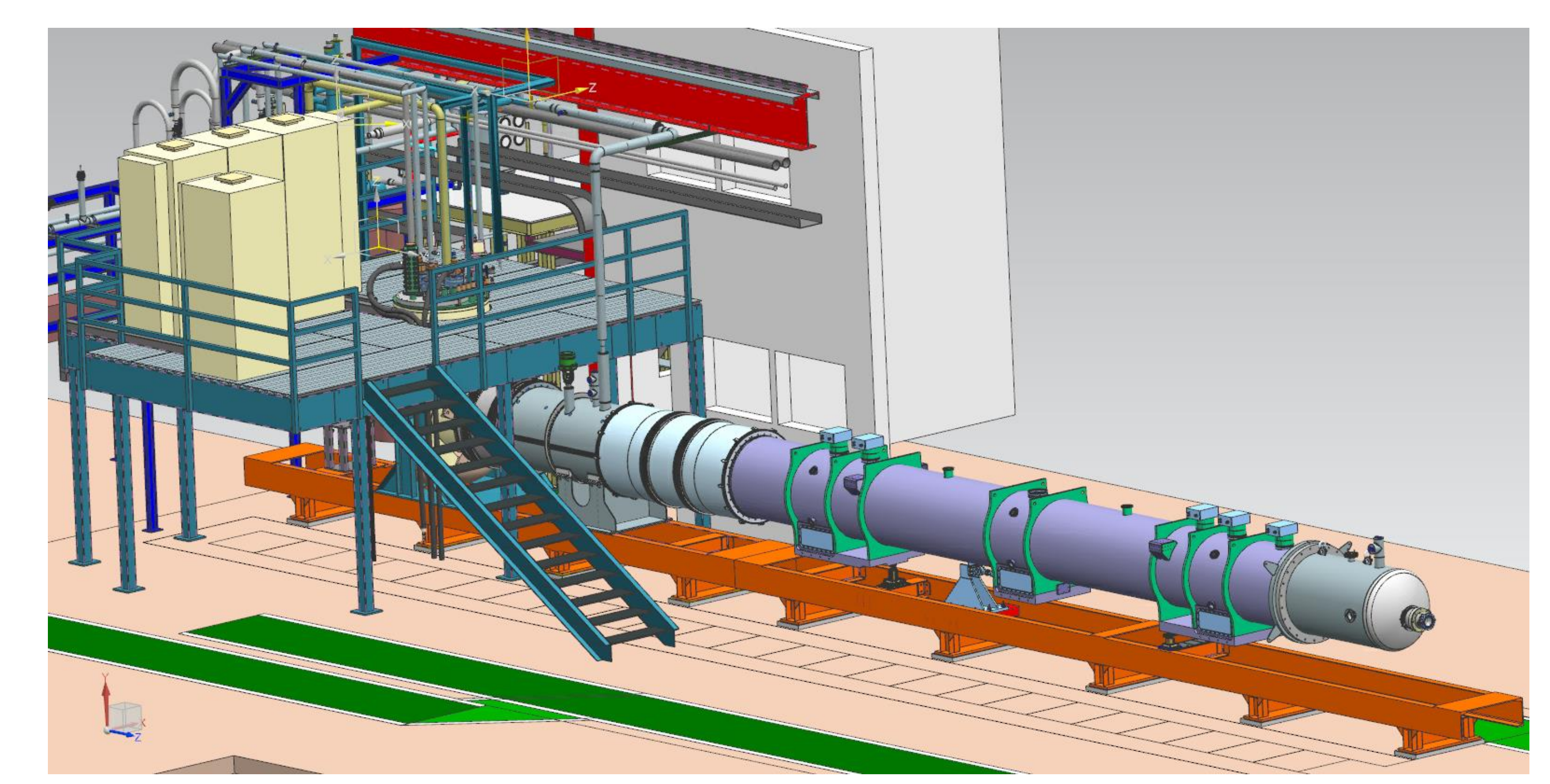

Test Stand 4 model layout for upcoming HiLumi-LHC Cryo-Assembly testing

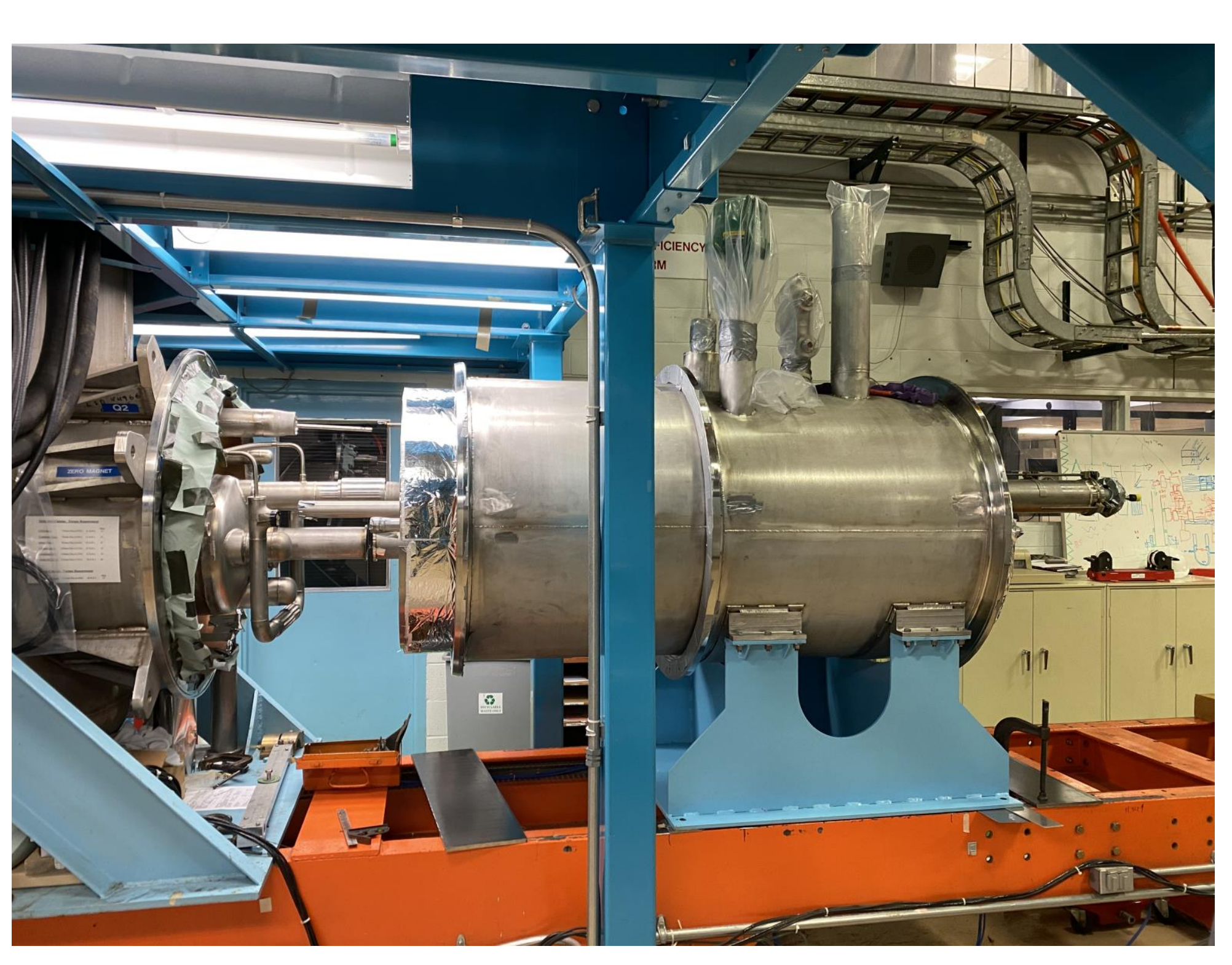

Adapter Box installation required for Stand 4 upgrades

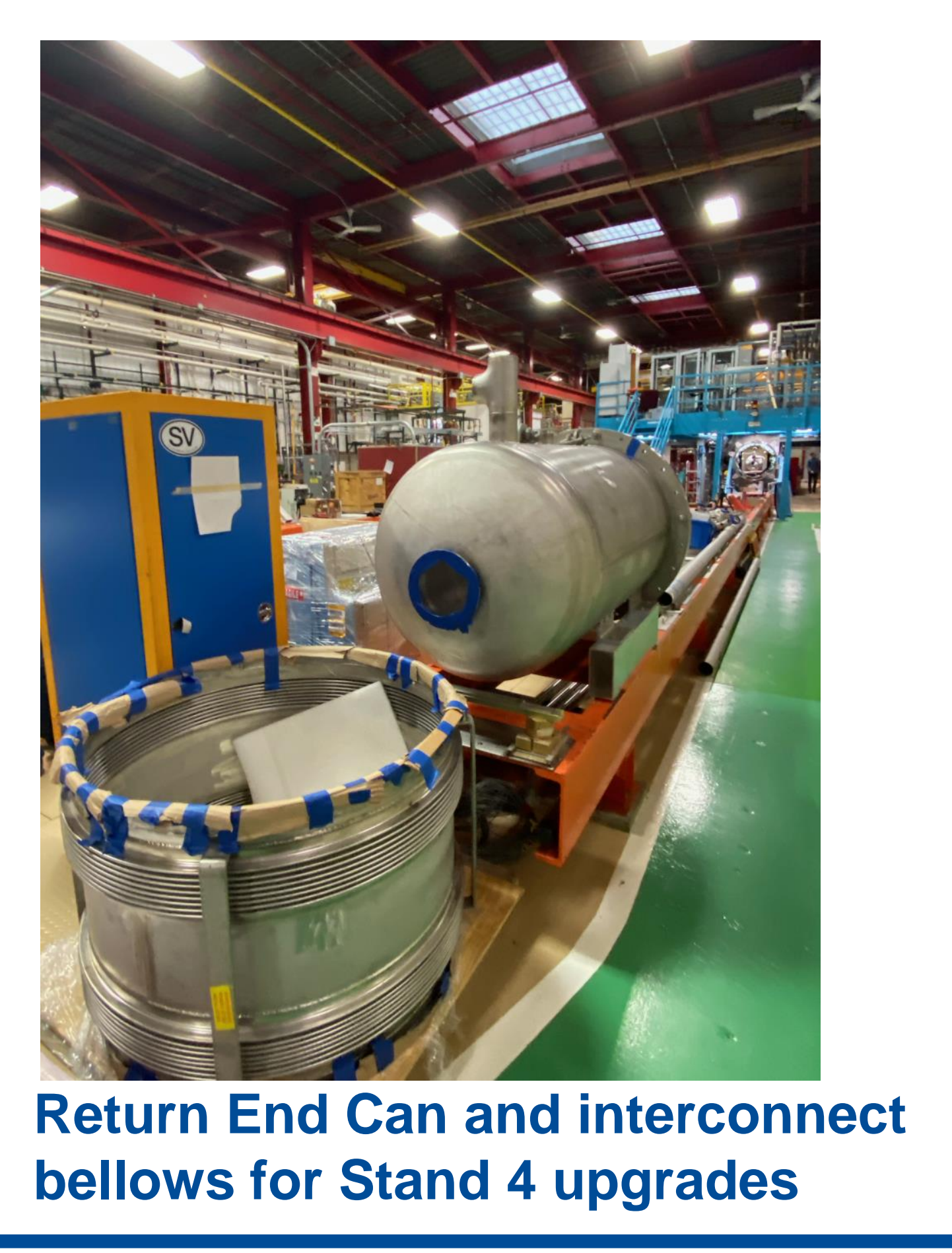

\section{High Field Vertical Magnet Test Facility (HFVMTF)}

A new, large diameter, test area will be constructed in IB1 to accommodate larger superconducting magnets approximately 1.3-m OD, 3.1-m length, and weighing less than 25-tons. The test area will act as an HTS cable testing facility for testing which will support the development of High Temperature

Superconductors in high dipole fields, and the testing of $16-20+T$ accelerator dipole magnets.

Civil construction of the test stand is expected to begin in the summer of 2020.

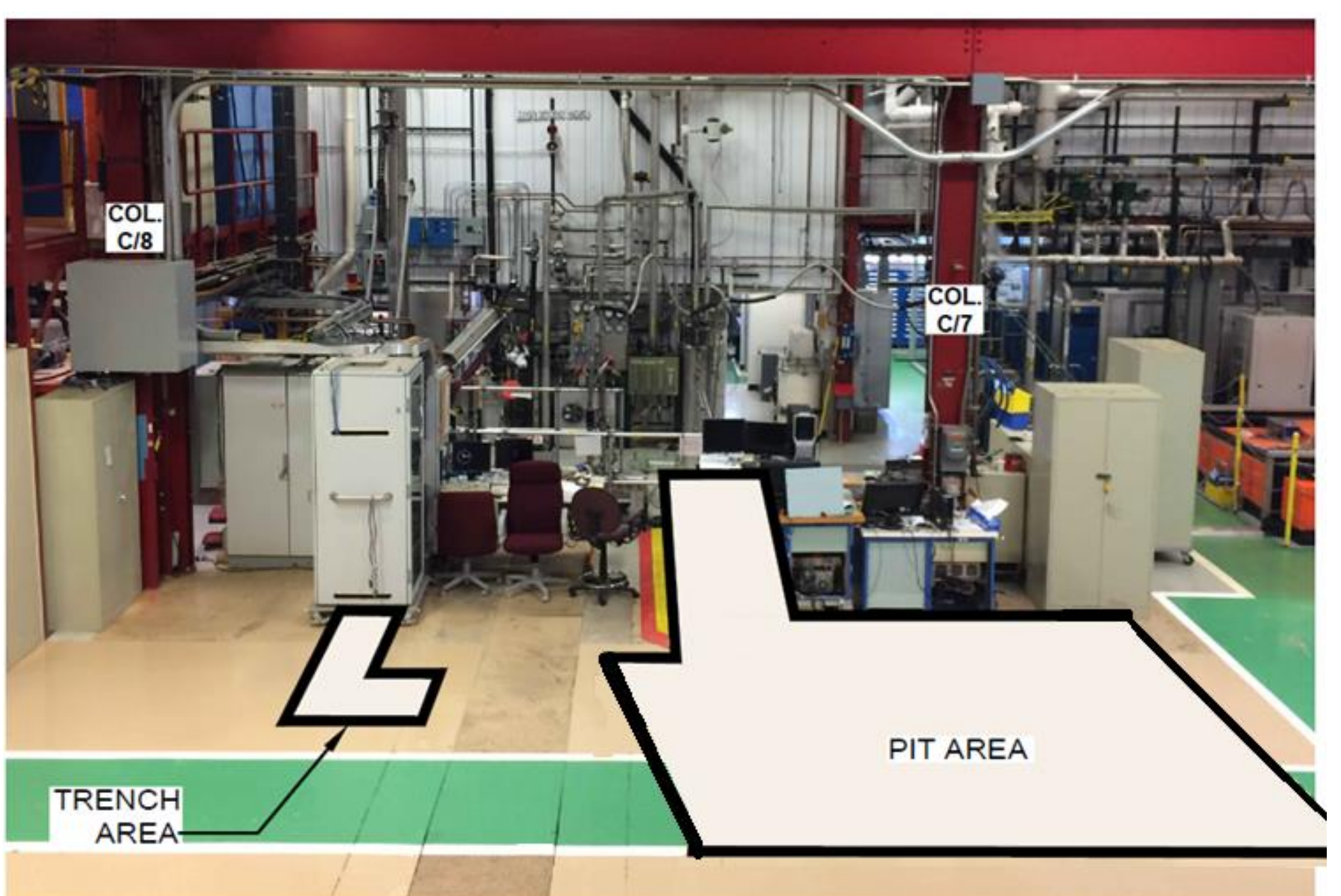

Designated Area of the new HFVMTF area

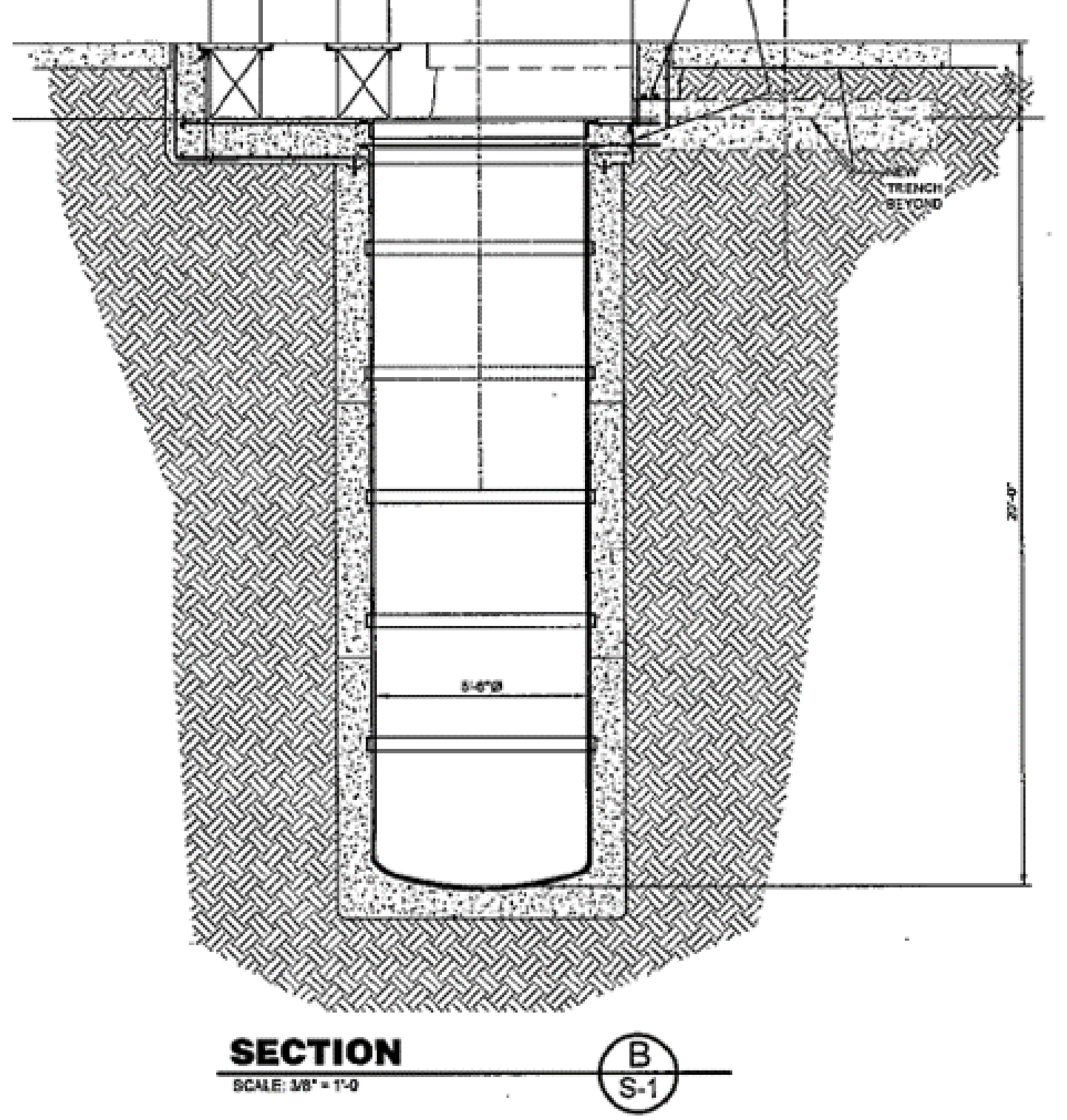

Civil construction plan showing the designated area for a new cryostat
This manuscript has been authored by Fermi Research Alliance, LLC under Contract No. DE-AC0207CH11359 with the U.S. Department of Energy, Office of Science, Office of High Energy Physics. 